\title{
The right pressure on Pompe
}

\section{Sara Carneiro ${ }^{1}$, Mauro Pereira' ${ }^{1}$, Carolina Gonçalves' ${ }^{1}$ Miguel Caridade ${ }^{1}$, Celina Oliveira ${ }^{1}$}

${ }^{1}$ Department of Anesthesiology - Braga's Hospital

\section{Background}

Pompe disease (PD) is a rare and progressive autosomal recessive disorder caused by a deficiency of the enzyme acid $\alpha$-glucosidase that degrades the glycogen into glucose in the lysosomal and is found mainly in skeletal and cardiac muscle. The presentation of this disorder depends on the age of onset, how quick it evolves and the degree of organ involvement. Lateonset disease presents as slowly progressive myopathy with or without lung involvement and no severe cardiac involvement ${ }^{1}$. Here we report the anesthetic management of a patient with late-onset PD.

\section{Case Report}

\section{Male \\ 51 years old \\ PD}

Restrictive respiratory syndrome requiring NIPV

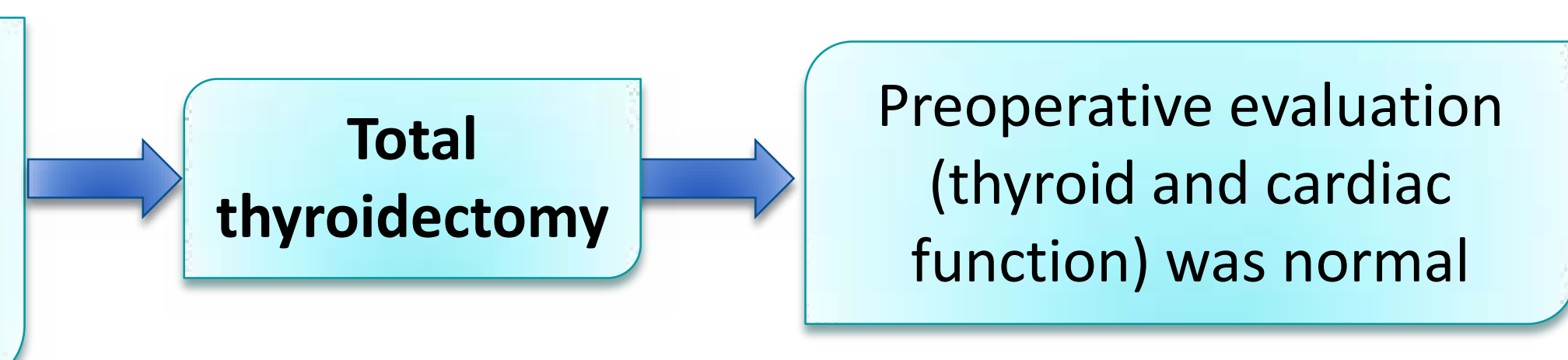

(thyroid and cardiac

function) was normal
Protocol Prevention of

Malignant Hyperthermia
ASA standard monitoring

(invasive blood pressure, neuromuscular and anesthetic depth monitoring)
Propofol

Remifentanil

Rocuronium

$\left.\begin{array}{c}\text { Immediate postoperative } \\ \text { period }\end{array} \quad \begin{array}{c}\text { High Dependency } \\ \text { Care Unit }\end{array}\right)$ CPAP $\begin{gathered}48 \text { hours with } \\ \text { excellent adaptation }\end{gathered}$

\section{Discussion}

Most information on anesthetic approach of PD comes from cases with onset in childhood, with few reports in adults. The progressive loss of pulmonary muscle function heightens the risk of aspiration, atelectasis, infection and respiratory failure in the perioperative period. Early institution of NIPV proved effective in preventing these complications and minimizing complications associated with prolonged ventilation. The prevention of $\mathrm{MH}$ should also be considered in these patients.

\section{Conclusion}

The perioperative management of patients with PD requires a multidisciplinary team approach, including anesthesiology, pulmonology and neurology. Early institution of NIPV and patient adaptation is paramount in preoperative optimization and allows a faster recovery of respiratory function in the postoperative period.

\section{References}

1.Pompe disease diagnosis and management guideline. Genet Med, 2006 May;8(5):267-88.

2.Combined general and epidural anesthesia for major abdominal surgery in a patient with Pompe disease. J Anesth. 2010 Oct;24(5):768-73 